\title{
Interpretations, perspectives and intentions in surrogate motherhood
}

Liezl van Zyl and Anton van Niekerk University of Waikato, New Zealand and University of Stellenbosch, South Africa respectively

\begin{abstract}
In this paper we examine the questions "What does it mean to be a surrogate mother?" and "What would be an appropriate perspective for a surrogate mother to have on her pregnancy?" In response to the objection that such contracts are alienating or dehumanising since they require women to suppress their evolving perspective on their pregnancies, liberal supporters of surrogate motherhood argue that the freedom to contract includes the freedom to enter a contract to bear a child for an infertile couple. After entering the contract the surrogate may not be free to interpret her pregnancy as that of a non-surrogate mother, but there is more than one appropriate way of interpreting one's pregnancy. To restrict or ban surrogacy contracts would be to prohibit women from making other particular interpretations of their pregnancies they may wish to make, requiring them to live up to a culturally constituted image of ideal motherhood. We examine three interpretations of a "surrogate pregnancy" that are implicit in the views and arguments put forward by ethicists, surrogacy agencies, and surrogate mothers themselves. We hope to show that our concern in this regard goes beyond the view that surrogacy contracts deny or suppress the natural, instinctive or conventional interpretation of pregnancy.

(Fournal of Medical Ethics 2000;26:404-409)
\end{abstract}

Keywords: Surrogate motherhood; parental rights and responsibilities

\section{Introduction}

Liberal individualists typically argue that the right to enter surrogacy arrangements is a part or natural extension of the right to personal autonomy. To prohibit or invalidate such contracts would be to violate women's right to self determination and reinforce the negative stereotype of women as incapable of full rational agency. Many opponents of the practice, including ourselves, ${ }^{1}$ have expressed a concern that surrogacy contracts can be dehumanising and alienating since they deny the legitimacy of the surrogate's perspective on her pregnancy. In response to this concern Hugh McLachlan argues that there need not only be one interpretation of one's pregnancy that is appropriate; people can value the same thing or activity in different ways: to make commercial surrogacy illegal would be "to prohibit mothers from making other particular interpretations of their pregnancies which they might (and sometimes do) want to make". ${ }^{2}$ Laura Purdy thinks this concern is based on an image of ideal motherhood that makes a disconcerting appeal to nature, thus ignoring the efforts of the women's movement to transcend the identification of women with nature. She argues that there will always be women who love being pregnant but who do not particularly enjoy child rearing, and that it would be regrettable if social pressure to live up to the idealised version of motherhood prevented them from providing infertile women with babies they could not otherwise have. For some women pregnancy and childbirth are not only a route to a child, but a desired end in itself, and this desire must count for something with those who want to validate women's experiences of gestation and labour. ${ }^{3}$ In much the same way, Lori Andrews sees surrogate motherhood as an outcome of the women's liberation movement. One of the hallmarks of feminism, she says, is the view that "biology is not destiny". Equal treatment of the sexes requires that decisions about men and women be made on other than biological grounds. For some women, the freedom gained from the knowledge that not all women relate to all pregnancies in the same way added up to the freedom to become surrogate mothers. ${ }^{4}$

It follows from the liberal view that the right to privacy and autonomy can only be legitimately curtailed if there is a significant risk that innocent third parties will be degraded or harmed. There is no evidence to suggest that surrogacy is harmful to children, and we agree that it is more likely that banning or criminalising surrogacy would result in substantial harm to children. We have also argued elsewhere that surrogacy does not necessarily constitute the commodification or degradation of children. ${ }^{5}$ But we do not think that our moral concerns with contract pregnancy are exhausted after having considered women's freedom to enter agreements and the possible harm to children. It is also necessary to examine the relationship between the surrogate mother and the fetus/child. The liberal individualist position tends to disregard the (to our mind) obvious fact that reproductive labour is not only a biological process that results in the production of an infant at the end of the process. Pregnancy and childbirth are not simply individualistic acts, but also, and perhaps more importantly so, social acts. When a woman signs a surrogacy 
contract, she does not only commit herself to undergo certain procedures, perform certain actions and refrain from doing others. She commits herself to (trying to) conceive, bear and give birth to another human being, and in the process does form some kind of relationship with it. In other words, the surrogate's perspective on her pregnancy also constitutes an interpretation of her (social and moral) relationship with the fetus/child.

Contracts cannot prescribe or direct the parties' feelings and perspectives, but they do affect what is considered an appropriate perspective within that context. An appropriate perspective would, at the least, be one that facilitates the parties' ability to honour the terms of the contract. As McLachlan writes, when a woman enters a surrogacy agreement "she is not 'free' to imagine that she has not become a commercial surrogate mother nor 'free' to interpret her pregnancy as the pregnancy of a non-surrogate mother. Such is the nature of contracts." Whereas the bond between a pregnant woman and her unborn child is usually an integral and appropriate part of her pregnancy, McLachlan argues that perhaps, in the case of commercial surrogate motherhood, such a bond is not and should not be integral to the pregnancy. ${ }^{6} \mathrm{He}$ does not say, however, what an appropriate interpretation of a contract pregnancy might involve. In this paper we examine some of the ways in which a surrogate mother may interpret her pregnancy and her relationship to the child she conceives, carries and gives birth to. Before we can even begin to address issues surrounding women's ability to enter into such contracts as autonomous agents, we need to answer the more fundamental question: "What does it mean to become a surrogate mother?"

\section{Conception in the mind}

The first way in which a surrogate mother may interpret her relationship with the fetus is "I am pregnant with someone else's child". In a sociological study conducted by Ragoné surrogates are quoted as saying: "I never think of the child as mine. After I had the baby, the mother came into the room and held the baby. I couldn't relate that it had any part of me"; "I don't think of the baby as my child. I donated an egg I wasn't going to be using"; "The baby isn't mine. I am only carrying the baby"; and "I am strictly the hotel". Hence both gestational and genetic surrogate mothers overlook the biological relationship by reasoning that the decisive feature of parenthood is the choice or intention to become a mother. She might say to herself: "I would have had a child if I wanted one, but I did not want a child". In the same way the commissioning mother uses the idea of intentionality to resolve her lack of biological relatedness to the child, reasoning that her role takes precedence over the surrogate's role since it was her desire for a child that facilitated the pregnancy; hence the notion "conception in the mind".

The view that parenthood should be established on the basis of contractually stated intentions instead of a biological relationship is becoming increasingly popular among legal scholars, feminists, surrogacy agencies and the general public. From this perspective, the difference between genetic and gestational surrogacy is not important, since in both kinds of cases the pregnancy was initiated by the commissioning parents. In an act drafted by the National Conference on Uniform State Laws and recommended for enactment in the United States, it is stated: "Upon birth of a child to the surrogate, the intended parents are the parents of the child and the surrogate and her husband, if she is married, are not the parents of the child". ${ }^{8}$ Within this context the term "parents" refers to legal parents, that is, the set of parents which has the legal right and responsibility to raise the child. Yet most surrogacy agencies encourage the view that the "intended parents" are the only real parents, whereas the surrogate is not a real mother because she did not conceive the child with that end in mind. She simply acts as a gestational host or temporary caregiver to the developing fetus which, from the moment of conception, belongs to the intending parents. Hence, we are made to believe, it would not be appropriate for the surrogate to see herself as pregnant with her child, since she has voluntarily relinquished or sold her parental rights to the intending couple.

\section{Logically untenable}

If we leave aside, for the moment, the question regarding who should be the legal parents of the child after its birth, it becomes clear that it is logically untenable for a woman to think of herself as pregnant with someone else's child. We may grant that pregnancy and childbirth are not essential features of the parent-child relationship (for then no man will ever be a father), but neither is it feasible to suggest that intentionality is the defining feature of parenthood. This relationship cannot be made entirely contingent upon choice, however voluntary or informed that decision, which is shown by the simple fact that men and women may become parents without them ever, explicitly or implicitly, intending or agreeing to do so. If a woman only becomes aware of her pregnancy when she goes into labour (as occasionally happens), are we to believe that she does not thereby become a mother, or that she gives birth to an orphan, because she never consented to becoming a mother? It is true that legal parenthood may, to a certain extent, be determined by agreements or contracts, but the fact of parenthood is not contingent upon an agreement. One may lose parental rights if one is guilty of child neglect or abuse, but one does not thereby become an "ex-parent". One may also waive or transfer parental rights and responsibilities, as happens in the case of adoption, but one does not thereby cease to be a parent. When a woman violates an agreement with her sexual partner to avoid pregnancy, he nevertheless becomes the father of that child. He might complain that he was tricked into fatherhood, but cannot deny his fatherhood. 
Apart from its many counterintuitive implications, the attempt to specify intentionality as the essential feature of parenthood is morally unacceptable since it is based on an implicit view of children as objects. To deny that the surrogate is the mother of the child amounts to viewing the relationship as one of ownership, the surrogate as a "human incubator" and the child as the "product" who bears no relationship to her other than its partly being the result of her physical labour. If, for instance, I sell property rights to my car, it is no longer my car. But if I sell or lose parental rights, there remains a sense in which the child is my child, even if I have ceased acting as its parent. Although I could still harbour some sentimental feelings towards the car I sold, I have no claim to be recognised by others as having a relationship with it. But because emotional ties are central to the parent-child relationship, they cannot be so easily ignored. New parental bonds can be created, but their creation does not eliminate or cancel an already existing bond.

\section{Prenatal adoption}

A second possible interpretation of surrogate motherhood, suggested by the above arguments, acknowledges the fact that the surrogate is or becomes a mother, but denies that she has any parental rights or responsibilities. What is being bought by the commissioning couple is not the child itself, but the "preconception termination of the mother's parental rights". ${ }^{9}$ From the moment of conception the fetus/child would therefore have two real mothers (-to-be), but only one legal mother (-to-be). In this sense the contract does not require the surrogate to deny that she is or becomes a mother. It only requires her to hand over the child to the set of parents which has acquired the right to raise it. Those who favour this interpretation typically appeal to the infertile couple's right to "noncoital reproduction". They acknowledge that the child may have more than one set of parents, but think that it is in the child's best interests if a primary family is chosen before its birth. If a conflict over parental rights arises after the birth, respect for the autonomy of couples and surrogates requires that the preconception agreement, which made the very existence of the child possible, should prima facie be determinative, just as it would be with sperm or egg donors. ${ }^{10}$

Among those who support the prenatal separation of biological parenthood and parental rights and responsibilities is Judith Jarvis Thomson. In her well-known paper on abortion she argues that we cannot have any special responsibilities towards someone unless we have voluntarily assumed them. A set of parents do not simply by virtue of their biological relationship to the child who comes into existence have a special responsibility for it. They may wish to assume responsibility for it, or they may not wish to. The child has no right against its mother for care and protection, unless it be implicitly or voluntarily conferred upon it at some stage of its development: "If a set of parents do not try to prevent pregnancy, do not obtain an abortion, and then at the time of birth of the child do not put it up for adoption, then they have assumed responsibility for it, have given it rights, so that they cannot now withdraw support from it at the cost of its life because they now find it difficult to go on providing for it". ${ }^{11}$ This argument is based on the liberal view that moral requirements are either general duties which we have towards everyone impartially, or specific obligations which are only formed by voluntary agreements. In the surrogacy context the implication of this view is that the surrogate does not, simply by virtue of her biological condition, have any special responsibilities or rights towards the fetus/infant. Although the woman intentionally and voluntarily becomes and remains pregnant, she had entered into a preconception agreement with another couple whereby she explicitly surrenders or transfers these rights and responsibilities to them. The responsibilities the surrogate has towards the fetus during pregnancy are not based on her own independent relation to the fetus but instead form an aspect of her contractual relation to the couple and the pregnancy she undertakes on their behalf. It is only as part of the surrogacy agreement that the fetus has acquired a right to use and occupy the woman's body. The commissioning couple may therefore prescribe the surrogate's behaviour during pregnancy, including obstetrical care, abstinence from possibly harmful substances, amniocentesis and even abortion.

\section{Mutual obligations}

One objection to surrogacy contracts is that they presuppose that a woman has no intrinsic moral responsibility for a child she conceives and no rights to a relationship with him or her. Cahill argues that these arrangements insist on free choice about human relations to an extent that constitutes a virtual denial of important material and physical aspects of the relations of parenthood, and of moral obligation in general: "Individuals cannot choose in all cases whether they have a certain moral obligation. The mutual obligations of biological family members - children, parents, siblings - are a paradigmatic case of obligations that one cannot simply decide do not exist". ${ }^{12}$ Similarly, in its assessment of the social and moral dimensions of surrogacy the New York Task Force states that "parents have a profound moral obligation to care for their offspring. Our legal and social norms affirm this obligation by requiring parents to care for their children's physical and emotional wellbeing. Surrogate parenting is premised on the ability and willingness of women to abrogate this responsibility without moral compunction or regret. It makes the obligations that accompany parenthood alienable and negotiable." ${ }^{13}$ What possibly underlies this objection is the fear that parental responsibilities would be assumed, transferred, reclaimed and retransferred at the whim of people who cannot quite make up their minds. After all, if parental rights and duties are contingent upon a decision, there seems to be no reason why the parties cannot agree to change its terms whenever it suits them, 
and this would obviously be detrimental to the child's welfare. To discard this fear, and following Thomson's reasoning, we could simply insist that the original contract be binding, that the parties be held to their contractually stated intentions.

Yet we think there is a more intimate way in which parenthood and parental rights and obligations are connected, regardless of intentions, so that the above objection cannot be that easily rejected. We cannot, as Andrews ${ }^{9}$ maintains, terminate parental rights and duties prior to conception. Legal norms relating to parental duties affirm, rather than create, already existing moral obligations. We cannot, in the available space, develop an account of the origin or foundation of parental obligations, and can only note that Western societies have for a long time embraced the notion that parents have a profound moral obligation to care for their offspring. It is also widely accepted that this obligation commences well before birth. For instance, a father's obligation to his child begins with his support and care of the pregnant woman. The question to be asked is therefore whether we, as a society, are ready to discard these conventions, to view family relationships as morally irrelevant, with rights and duties instead being conferred or assumed by mutual agreements. One of the implications of accepting the separation of parenthood (as a relationship rooted in biology) and parental rights and obligations (as a relationship based on voluntary agreements), is that we could not expect a father to fulfil certain obligations if he never consented to do so. He would not be able to demand an abortion, of course, and neither is his status as a parent contingent upon a decision. But one can, along "biology is not destiny" lines, argue that he should not be expected to assume parental responsibilities simply by virtue of a biological relationship. Because the woman decided not to abort, she is responsible for the child.

\section{Ambiguous relationship}

The prenatal separation of biological and moral relationships places the surrogate in a highly ambiguous relationship with the fetus. As a woman who has a right to bodily integrity, she has a right to an abortion, but as a surrogate, she would have no right to determine the destiny of the fetus. Indeed, through entering the contract she has given the fetus a right to inhabit her body, which she cannot withdraw without the couple's consent. Ragoné questioned a number of surrogates who were "opposed to abortion for themselves", but who acknowledged that they would undergo an abortion if that was the couple's decision. ${ }^{7}$ Although surrogacy contracts usually make it clear that the stipulation regarding abortion is unenforceable, the surrogate's having (or not having) an abortion against the couple's wishes would still constitute breach of contract. And if the pregnant woman engages in behaviour that is potentially harmful to the child, it would not involve a neglect of parental responsibilities (since she has none), but would constitute a violation of the legal agreement with the intending parents. (One can only wonder what the appropriate penalty for such a breach would be.)

The attempt to separate biological and moral relationships ignores the fact that the surrogate has, by virtue of her being the gestational mother, certain moral responsibilities to the fetus, and that these can only be affirmed by any legal contract she may enter into. In other words, her obligation is directly to the fetus, not indirectly through an agreement with the intending parents. Surrogacy is not analogous to child-caring services because, once she has conceived, the surrogate finds herself in a (for all practical purposes) irreplaceable, intimate relationship with someone who is totally dependent on her for its wellbeing. Unless she has an abortion or miscarriage, this link cannot be severed nor can these duties be relinquished before birth, simply because there is no one else who could take over responsibility for the welfare of the developing fetus. In this regard the difference between gestational and genetic surrogacy is irrelevant. The surrogate's obligations during pregnancy stem from her proximity to the fetus and are not contingent upon an agreement with the commissioning couple. The surrogate cannot choose not to be morally responsible for the fetus while it remains in her womb. In this sense, biology certainly is destiny.

\section{Commissioned adoption}

The above line of thought leads to a third possible interpretation of surrogacy, where contractually stated intentions only determine who the social parents of the child would be. What is being paid for or transferred is therefore not motherhood, nor preconception termination of parental rights, but the right and responsibility to rear the child. The surrogate would be registered on the birth certificate, with the child subsequently being adopted by the intending parents. The surrogate's perspective on her pregnancy could therefore be: "I am expecting my child, and am both morally and legally responsible for its welfare, although I intend to relinquish parental rights to the adopting couple immediately after birth", or simply: "I do not intend to raise my child".

This interpretation is in line with the provisions of English law. (According to the Human Fertilisation and Embryology Act the birth mother, whether or not she is the genetic mother, is the legal mother until and unless an adoption procedure is undertaken.) But it is quite far removed from the way in which surrogacy agencies encourage women to interpret their pregnancies. Ragoné found that the surrogate's perception that the child is not her own tends to shape her entire experience of surrogacy. Her ability to separate herself from her pregnancy and child is reinforced by psychologists employed by these agencies. In one instance where therapy designed to maintain the "desired state of mind" was withdrawn after the agency went bankrupt, all three surrogates expressed intense separation anxiety: "When the support services are removed and the structure of the program dissolves, it is difficult, 
if not impossible, to maintain the prescribed and desired boundaries between the surrogate and her child; hence, surrogates report feelings of loss, pain, and despair when parting with the child". ${ }^{14}$ The very success of surrogacy arrangements therefore depends on how well the surrogate can deceive herself into believing that she is not a mother but simply a temporary care-giver. Whereas the surrogate's belief that she is not pregnant with her child is a clear form of self deception, unveiling it as such almost certainly would give rise to greater distress and alienation at having to relinquish a child she knows to be hers.

For the commissioning parents thinking of surrogacy as analogous to adoption has the disadvantage that they cannot view the surrogate simply as "the kind woman who made it possible for them to have their own family". Even to acknowledge that they would forever be indebted to her, or that money cannot compensate her for this great service would still be to deny the fact that there will always be a sense in which she is a mother of their child. While surrogacy arrangements give rise to more than one maternal bond or real mother, participants subsequently seek to deny this by insisting upon modelling their households directly along the lines of the nuclear family. (This is perhaps best symbolised by the infertile woman who wore a little pillow under a maternity gown when she visited her husband's family, and would not let their Mexican surrogate leave the house.) The very point of surrogacy is usually to receive the child unencumbered by any ongoing relationship with the woman who "produced" it.

Thinking of contract pregnancies as "commissioned adoptions" requires that both parties acknowledge the surrogate's motherhood. If the parent-child relationship constitutes more than can be captured in the language of legal rights and responsibilities, the social parents should recognise the surrogate's role by including her in the child's life in an ongoing and intimate way. They cannot insist on traditional ends if they use non-traditional means. Because parenthood is not equivalent to ownership, transferring parental rights can only create more parents; it cannot annul an already existing bond. The implication of this for the surrogate mother is that she can only take her own moral responsibilities towards the child seriously if she is well acquainted with the intending parents before entering the agreement. Although there are clear similarities, it is important to notice the differences between commissioned and traditional adoptions. In the adoption context, circumstances prevent those morally responsible for the child from rearing it. Finding suitable parents among the many people wanting to adopt a child is a way of taking their responsibility for the child's welfare seriously. By contrast, the surrogate is not in a position to refuse transfer of legal parenthood if she discover that the intending parents are not suitable for raising the child. The surrogacy agreement has given rise to the formation of a specific set of expecting parents. The only way in which a surrogate mother can take her moral obligations towards the child seriously is by making sure well before conception that the intending parents are both willing and capable of caring for the child. For these reasons altruistic surrogacy is morally preferable to commercial surrogacy. In other words, the moral acceptability of surrogacy does not turn on whether money is exchanged in return for parental rights or childbearing services, but on the nature of the relationship between the commissioning parents and the surrogate mother.

\section{Conclusion}

One may agree with the liberal view that women may interpret their pregnancies and their relationship with the fetus in different ways. A pregnant woman cannot, however, deny that she finds herself in such a relationship, and neither should she deny her moral responsibility for the fetus's welfare. Contractually stated intentions cannot determine who the "real mother" is or whether the birth mother has any moral responsibilities towards her fetus. Affirming the surrogate's motherhood does not, however, require a denial of the intending parents' bond with their child. Against those who view the genetic relationship as the essence of parenthood, as well as those who propose that intention be recognised as the essence, we have argued that we should not attempt to isolate the essence or definitive aspect of parenthood since parental bonds are not mutually exclusive. To be a parent, one must possess some of the defining features of parenthood, such as a gestational, genetic, intentional or social relationship, but all of these features need not be common to all parents. Acknowledging the possibility of multiple parenthood has the implication that the adoptive or intending parents cannot insist on modelling their family directly along the lines of the nuclear family. Having reinterpreted parenthood, we should also be prepared to reinterpret the family.

Liezl van Zyl, Dphil, is Lecturer in Philosophy at the University of Waikato, New Zealand. Anton van Niekerk, Dphil, is Professor of Philosophy at the University of Stellenbosch, South Africa

\section{References}

1 Van Niekerk A, Van Zyl L. The ethics of surrogacy: women's reproductive labour. fournal of Medical Ethics 1995;21:345-9. 2 McLachlan HV. Defending commercial surrogate motherhood against Van Niekerk and Van Zyl. Fournal of Medical Ethics 1997;23:344-8. In this paper McLachlan gives a detailed explanation of the relation between morality and the law, arguing that the possible immorality of surrogacy arrangements does not constitute good reason for prohibiting them. We absolutely agree that immorality is no necessary ground for illegality. But our original paper (see reference 1) does not contain single phrase to suggest that we were in favour of contain a single phrase to suggest that we were in favour of banning surrogacy on the grounds of our moral convictions. Our paper was about the moral status of surrogacy, and not about its desired lup a straw man respunse sis the up a straw man argument and shooting it down. Our focus in the present paper is not with the complex legal issues surrounding the question whether surrogacy contracts should 
be enforced, regulated or criminalised. Instead, we examine some of the moral implications of a surrogate mother's interpretation of her pregnancy and her relationship with the fetus/child.

3 Purdy LM. Another look at contract pregnancy. In: Holmes $\mathrm{HB}$, ed. Issues in reproductive technology: an anthology. New York and London: Garland Publishing, 1992: 309-11

4 Andrews LB. Surrogate motherhood: the challenge for feminists. In Gostin L, ed. Surrogate motherhood: politics and pri1990: 168.

5 Van Niekerk AA, Van Zyl LL. Commercial surrogacy and the commodification of children: an ethical perspective. Medicine and Law 1995;14:163-70.

6 See reference 2: 346-7.

7 Ragoné H. Surrogate motherhood: conception in the heart. Boulder, San Francisco, Oxford: Westview Press, 1994: 75-8.

8 Uniform Status of Children of Assisted Conception Act, drafted by the National Conference of Commissioners on Uni- form State Laws in Washington, DC, 1988 Jul 29-Aug 5: section 8 a.

9 See reference $4: 170$

10 Robertson JA. Procreative liberty and the state's burden of proof in regulating noncoital reproduction. In Gostin L, ed. Surrogate motherhood: politics and privacy. Bloomington and Surrogate motherhood: politics and privacy. Bloo

11 Thomson JJ. A defence of abortion. Philosophy and Public Affairs 1971;1:65.

12 Cahill LS. The ethics of surrogate motherhood: biology, freedom, and moral obligation. In Gostin L, ed. Surrogate motherhood: politics and privacy. Bloomington and Indianapolis: Indiana University Press, 1990:154, 163.

13 New York State Task Force on Life and the Law. Surrogate parenting: analysis and recommendations for public policy. New
York: New York State Task Force on Life and the Law, 1988 May.

14 See reference 7: 78-80. 